\title{
Papers
}

\section{Effect of preoperative abstinence on poor postoperative outcome in alcohol misusers: randomised controlled trial}

\author{
Hanne Tønnesen, Jacob Rosenberg, Hans J Nielsen, Verner Rasmussen, Christina Hauge, \\ Ib K Pedersen, Henrik Kehlet
}

\begin{abstract}
Objective To evaluate the influence of preoperative abstinence on postoperative outcome in alcohol misusers with no symptoms who were drinking the equivalent of at least $60 \mathrm{~g}$ ethanol/day.

Design Randomised controlled trial.

Setting Copenhagen, Denmark.

Subjects 42 alcoholic patients without liver disease admitted for elective colorectal surgery.

Interventions Withdrawal from alcohol consumption for 1 month before operation (disulfiram controlled) compared with continuous drinking.

Main outcome measures Postoperative complications requiring treatment within the first month after surgery. Perioperative immunosuppression measured by delayed type hypersensitivity; myocardial ischaemia and arrhythmias measured by Holter tape recording; episodes of hypoxaemia measured by pulse oximetry. Response to stress during the operation were assessed by heart rate, blood pressure, serum concentration of cortisol, and plasma concentrations of glucose, interleukin 6 , and catecholamines.

Results The intervention group developed significantly fewer postoperative complications than the continuous drinkers ( $31 \% v 74 \%, \mathrm{P}=0.02)$.

Delayed type hypersensitivity responses were better in the intervention group before $\left(37 \mathrm{~mm}^{2} v 12 \mathrm{~mm}^{2}\right.$, $\mathrm{P}=0.04)$, but not after surgery $\left(3 \mathrm{~mm}^{2} v 3 \mathrm{~mm}^{2}\right)$. Development of postoperative myocardial ischaemia $(23 \% v 85 \%)$ and arrhythmias (33\% v 86\%) on the second postoperative day as well as nightly hypoxaemic episodes ( $4 v 18$ on the second postoperative night) occurred significantly less often in the intervention group. Surgical stress responses were lower in the intervention group $(\mathrm{P} \leqslant 0.05)$.

Conclusions One month of preoperative abstinence reduces postoperative morbidity in alcohol abusers. The mechanism is probably reduced preclinical organ dysfunction and reduction of the exaggerated response to surgical stress.
\end{abstract}

\section{Introduction}

During recent years several studies have shown a threefold increase in postoperative morbidity in alcohol misusers who drink at least five drinks ( $\geqslant 60 \mathrm{~g}$ ethanol) a day. ${ }^{1-4}$ The misusers have prolonged hospital stay and need more secondary surgery. The most common complications are infections, cardiopulmonary insufficiency, and episodes of bleeding. The pathogenic mechanisms are probably preoperative immunosuppression, preclinical cardiac insufficiency, haemostatic imbalance, and an exaggerated response to surgical stress. ${ }^{2}$ In non-surgical patients such dysfunctions are often reversible after withdrawal from alcohol. ${ }^{5}$

We investigated the influence of 1 month of preoperative abstinence from alcohol on postoperative morbidity in a controlled randomised design.

\section{Methods}

\section{Protocol}

We planned to evaluate a minimal relevant difference above $50 \%$ between the groups. The complication rate in the alcohol misusers was estimated as $67-75 \% .{ }^{2}{ }^{4} \mathrm{We}$ were willing to accept a high type I failure because of the relatively few side effects of intervention compared with the poor outcome otherwise, whereas we would not overlook a possible benefit in this high risk group $(2 \alpha=0.10, \beta=0.05)$. The number of included patients was then calculated to $2 \times 18$. The inclusion criteria were alcohol misuse of five or more drinks (60 $\mathrm{g}$ of ethanol) a day without clinical or historical evidence of alcohol related illness (cirrhosis, hepatitis, pancreatitis, polyneuropathy, Wernicke-Korsakoff syndrome) in patients suffering from colorectal disease who probably required elective surgical intervention. Only patients without disseminated malignant disease or signs of bowel obstruction scheduled for intended radical surgery were included.

To avoid surgical delay the patients were included in the trial before the final decision for operation was made. Patients could therefore be excluded later by change of indication or date of operation. Other exclusion criteria were drug abuse, psychiatric disease (other than alcohol abuse), unfamiliarity with Danish language, and withdrawal of informed consent.

\section{Assignment}

Within each of three gastrointestinal surgical centres patients were randomised either to intervention, consisting of 1 month of preoperative withdrawal from alcohol and treatment with disulfiram $(800 \mathrm{mg}$ disulfiram taken during controlled supervision twice
Department of
Surgical
Gastroenterology,
Hvidovre Hospital,
University of
Copenhagen,
DK-2650 Hvidovre,
Denmark 
weekly until the week before surgery) or to control, which was the routine procedure. The allocation was based on computer generated random numbers. Information on intervention or routine procedure was enclosed in sealed, opaque envelopes with consecutive numbers (written on the envelope and inside on the information). This was performed by a colleague who did not otherwise take part in the study.

\section{Perioperative procedure}

Preoperative and intraoperative characteristics included the prognostic nutrition index, ${ }^{6}$ cardiac risk index, ${ }^{7}$ and ASA (American Society of Anesthesiologists) score $^{8}$ (table 1). Thirty patients underwent a liver biopsy during the operation, none had histological signs of hepatitis or cirrhosis. The others had normal results on ultrasound examination and computed tomography of the liver.

Routine prophylaxis included pulmonary physiotherapy; intravenous cefuroxime $3 \mathrm{~g}$ and metronidazole $1.5 \mathrm{~g}$ or ampicillin $2 \mathrm{~g}$, gentamicin $0.24 \mathrm{~g}$, and metronidazole $1 \mathrm{~g}$ at the start of anaesthesia; and low molecular weight heparin; and stockings (TED, Kendan, Vedbæh, Denmark) from the day before surgery until mobilisation. Bowel preparation was different in the three centres: oral saline solution, hyperosmolar electrolyte mixture (Klean Prep, Norgine Lim, Harefield, Middlesex), or no preparation

Table 1 Characteristics of patients undergoing colorectal resection, according to whether they abstained from alcohol in month before operation. Figures are medians (range) unless states otherwise

\begin{tabular}{|c|c|c|}
\hline Detail & $\begin{array}{l}\text { Intervention group } \\
\text { (no alcohol; } \mathrm{n}=16 \text { ) }\end{array}$ & Control group $(n=19)$ \\
\hline No of men & 16 & 16 \\
\hline Age (years) & $58(37-75)$ & $61(50-76)$ \\
\hline Body mass index $\left(\mathrm{kg} / \mathrm{m}^{2}\right)$ & $24(18-30)$ & $28(19-32)$ \\
\hline No of non-smokers & 7 & 8 \\
\hline Smokers (g/day) & $20(5-40)$ & $20(2-30)$ \\
\hline Prognostic nutrition index $(\%)^{\star}$ & $51(14-63)$ & $30(12-52)$ \\
\hline Cardiac risk index (points) & $3(3-15)$ & $3(3-10)$ \\
\hline ASA score & II (III-III) & II (IIIIII) \\
\hline No treated for chronic diseases: & 5 & $6 \dagger$ \\
\hline Heart failure & 2 & 1 \\
\hline Angina pectoris & 0 & 0 \\
\hline Hypertension & 1 & 4 \\
\hline Chronic bronchitis & 1 & 2 \\
\hline Asthma & 1 & 0 \\
\hline IDDM/NIDDM $\ddagger$ & 0 & 0 \\
\hline \multicolumn{3}{|l|}{ Operative procedure: } \\
\hline Resection of transverse colon & 1 & 1 \\
\hline Hemicolectomy & 2 & 3 \\
\hline Sigmoid resection & 3 & 4 \\
\hline Low anterior resection & 4 & 5 \\
\hline Rectal amputation & 1 & 1 \\
\hline Closure of stoma after Hartmann's resection & 5 & 5 \\
\hline Diagnosis benign/malignant: & $8 / 8$ & $9 / 10$ \\
\hline Dukes's type A & 1 & 0 \\
\hline Dukes's type B & 2 & 8 \\
\hline Dukes's type C & 5 & 2 \\
\hline Duration of surgery (min) & 185 (110-335) & $180(100-315)$ \\
\hline No who did not have transfusion & 12 & 15 \\
\hline Intraoperative transfusion (ml) & $900(600-2100)$ & $1350(600-3100)$ \\
\hline Intraoperative infusion (ml) & $2500(2100-7000)$ & $3000(1400-4500)$ \\
\hline
\end{tabular}

*Values above $50 \%$ are associated with increased postoperative morbidity. ${ }^{6}$

†One patient suffered from heart failure and hypertension.

fIDDM=insulin dependent diabetes mellitus; NIDDM=non-insulin dependent diabetes mellitus.

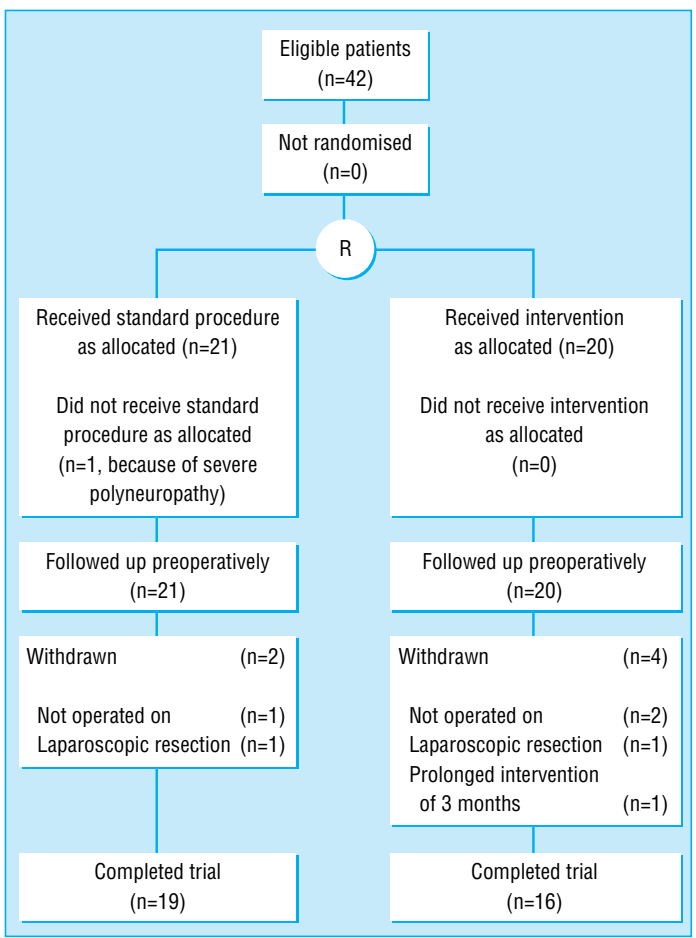

Fig 1 Trial profile of alcoholic patients who underwent colorectal resection. Intervention group abstained from alcohol for 1 month before operation

at all except for preoperative enema (Klyx, Ferring A/S, Copenhagen, Denmark).

Diazepam was used for premedication and intravenous midazolam, low dose fentanyl, nitrous oxide in oxygen, and isoflurane for general anaesthesia. All patients had epidural bupivacaine $(0.5 \%$ 4-10 $\mathrm{ml}$ ) plus morphine $(2-4 \mathrm{mg}$ ) followed by infusion (see below) for supplemental anaesthesia. Continuous epidural infusion of bupivacaine $(0.25 \%)$ and morphine $(0.05 \mathrm{mg} / \mathrm{ml})$ with a rate of $4-8 \mathrm{ml} / \mathrm{h}$ for $2-3$ days was used in addition to a non-steroidal anti-inflammatory drug or paracetamol for treatment of postoperative pain. Infusion of glucose was not given intraoperatively. After surgery all patients received supplemental nasal oxygen $(2 \mathrm{l} / \mathrm{min})$ until next morning. Further oxygen was given on specific indication only. No patient received oxygen on the second night. The patients were mobilised from the day of surgery and recommended to drink and eat freely, except for patients with a rectal anastomosis who had only liquids until the first bowel movement.

The patients were followed up after 1 month, and clinical complications that required treatment were noted within this period. A self care score system (ranging from 0 for normal function to 2 for complete dependence) was repeated daily by the nurses for fluid and food intake, personal and sanitary care, mobility, and mental needs. The maximum score was $12 .{ }^{2}$ Self care requirements were evaluated preoperatively and postoperatively until the 10th postoperative day. If a patient was discharged before then, the score on the last day in hospital was used for the remaining days.

Delayed type hypersensitivity was measured by a skin test (Multitest, Institute Merieux, Lyons, France) consisting of seven simultaneously applied delayed type hypersensitivity antigens: tetanus, diphtheria, 
streptococcus, tuberculin, proteus, candida, and Trichophyton. The test was applied 2 days preoperatively and at induction of anaesthesia. The cutaneous responses were read as the sum of the indurated areas after 48 hours.

The patients underwent continuous monitoring for electrocardiographic changes by Holter tape recording (Spacelabs 90205, Spacelabs, Redmond, Washington, United States) after the operation and until the third postoperative day, second operation, or assisted ventilation, whichever occurred first. Tachycardia was defined as heart rate above 100 beats/min; arrhythmias as measurable ventricular ectopic activity $(>10$ isolated ventricular beats/hour, polymorphic premature ventricular beats, or repetitive forms-that is, pairs, runs, or episodes of ventricular tachycardia) or atrial fibrillation; myocardial ischaemia as decrease in ST level on electrocardiography of more than $1 \mathrm{mV}$ or increase of more than $1.5 \mathrm{mV}$ from baseline measured at $60 \mathrm{~ms}$ from the $\mathrm{J}$ point. ${ }^{9}$ In two of the three centres arterial oxygen saturation was monitored during the first two postoperative nights (1100 pm to $700 \mathrm{am})$ at the same time as Holter tape recording, by pulse oximetry (Nellcor N-3000, Nellcor Puritan Bennett, Pleasanton, California). Episodic hypoxaemia was defined as a sudden decrease in arterial oxygen saturation of $5 \%$ or more from baseline and constant hypoxaemia as mean saturation $<90 \%{ }^{9}$

Central venous blood was obtained by cannulation of the external jugular vein at the start of the operation and 2, 4, 6, 8, 10 (but not later than $800 \mathrm{pm}$ ), and 24 hours later. Heart rate and blood pressure was routinely measured every 5 minutes during surgery and every 15 minutes in the recovery ward.

\section{Analysis}

Plasma glucose concentration was measured at the bedside (Photometer, Haemocue AB, Ängelholm, Sweden) and serum cortisol concentration at the department of clinical biochemistry (RIA 1277 Gammamaster, LKB-Wallac Oy, Turku, Finland). Blood for analysis of catecholamines was collected in ice cold tubes containing EGTA (ethyleneglycol-bis (aminoethylether)-tetra-acetic acid) and reduced glutathione. Plasma samples were separated within 10 minutes in a refrigerated centrifuge and stored at $-80^{\circ} \mathrm{C}$ until measurement by high pressure liquid chromatographic separation of radioenzyme labelled catecholamines ${ }^{10}$ (Amersham International, Buckinghamshire) with a sensitivity of $0.07 \mu \mathrm{mol} / \mathrm{l}$. The variation within and between assays for measurement of noradrenaline was $3.8 \%$ and $8.5 \%$ and for adrenaline was $4.2 \%$ and $12.2 \%$, respectively. Blood samples for interleukin 6 testing were collected on ice and followed the separating procedure for catecholamines. The tubes contained $7.5 \mu \mathrm{l} / \mathrm{ml}$ of ethylenediaminetetra-acetic acid and $12.5 \mu \mathrm{l} / \mathrm{ml}$ of aprotinin. Interleukin 6 was analysed by a commercially available enzyme linked immunosorbent assay (interleukin 6, Immunotech SA, Marseilles, France) with a detection limit of $3.9 \mathrm{pg} / \mathrm{ml}$. The variation within and between assays was $1.8 \%$ and $5.7 \%$. All analyses were performed blinded.
Table 2 Clinical complications after colorectal resection, according to whether patients had abstained from alcohol in month before operation

\begin{tabular}{|c|c|c|c|}
\hline Detail & $\begin{array}{l}\text { Intervention group } \\
\text { (no alcohol; } n=16 \text { ) }\end{array}$ & $\begin{array}{c}\text { Control group } \\
(n=19)\end{array}$ & $P$ value* \\
\hline No of minor complications: & 5 & 17 & \\
\hline Wound infections (requiring surgical intervention) & 3 & 4 & \\
\hline Wound haematoma (surgical intervention) & 0 & 1 & \\
\hline Pneumonia (stethoscopy and $x$ ray confirmation) & 0 & 5 & \\
\hline Thrombophlebitis (venography) & 1 & 0 & \\
\hline Haematemesis & 0 & 1 & \\
\hline Subileus (retention $\geqslant 7$ days) & 0 & 1 & \\
\hline Dehydration (readmission for IV rehydration) & 0 & 2 & \\
\hline Urinary infection $\left(\geqslant 10^{5}\right.$ bacteria/ml) & 1 & 2 & \\
\hline Fistula (external) & 0 & 1 & \\
\hline No of major complications: & 5 & 14 & \\
\hline Fascial rupture & 0 & 3 & \\
\hline $\begin{array}{l}\text { Intra-abdominal bleeding (requiring surgical } \\
\text { intervention and transfusion) }\end{array}$ & 0 & 1 & \\
\hline Intra-abdominal abscess (drainage) & 1 & 2 & \\
\hline Anastomotic leakage (surgical intervention) & 2 & 2 & \\
\hline Ileus (surgical intervention) & 0 & 1 & \\
\hline Cardiopulmonary insufficiency (intensive care) & 1 & 4 & \\
\hline $\begin{array}{l}\text { Acute myocardial infarction (increased enzymes, } \\
\text { ECG changes) }\end{array}$ & 0 & 0 & \\
\hline Sepsis (bacteriaemia and fever) & 1 & 1 & \\
\hline $\begin{array}{l}\text { Pulmonary embolism (positive ventilation/perfusion } \\
\text { scintigraphy) }\end{array}$ & 0 & 0 & \\
\hline $\begin{array}{l}\text { Psychosis (hallucinations requiring } \\
\text { pharmacological treatment) }\end{array}$ & 0 & 0 & \\
\hline \multicolumn{4}{|l|}{ No of patients with: } \\
\hline Any complication & $5 / 16$ & $14 / 19$ & 0.02 \\
\hline Major complications & $2 / 16$ & $8 / 19$ & 0.07 \\
\hline Minor complications & $4 / 16$ & $11 / 19$ & 0.09 \\
\hline \multicolumn{4}{|l|}{ Patints who required secondary surgery: } \\
\hline Intraperitoneal & $2 / 16$ & $8 / 19$ & 0.07 \\
\hline Superficial & $3 / 16$ & $4 / 19$ & 1.00 \\
\hline Mortality & $1 / 16$ & $2 / 19$ & 1.00 \\
\hline
\end{tabular}

*Fisher's exact test.

\section{Statistics}

Mann-Whitney test and Fisher's exact test were used for statistical analyses. Data monitored over time were compared by the area under the curve to reduce the number of tests. The level of significance was 0.05 . Data are given as median (range).

Ethics

The study was approved by the scientific ethics committees of Copenhagen (KA 92043). The ethical considerations before this study included randomisation to a group without intervention. In our opinion, it is not common practice to intervene against asympto-
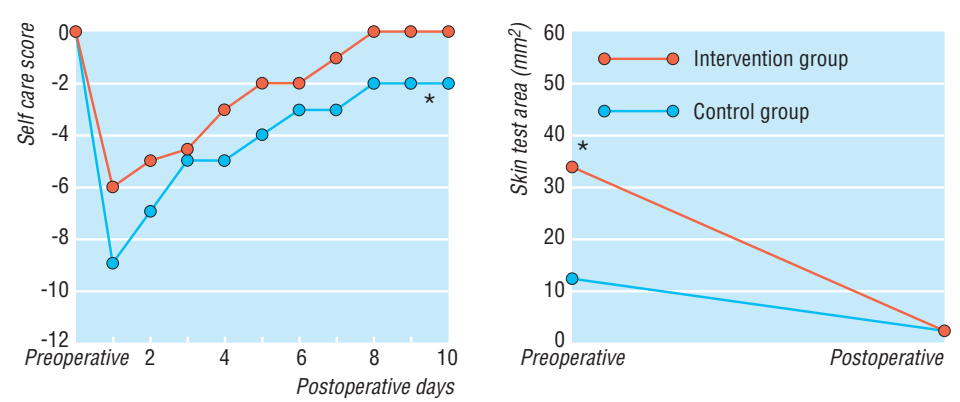

Fig 2 Median values for self care and skin test areas after colorectal surgery in alcohol misusers. *Significance between groups (area under curve) $\mathrm{P}=0.04$ for self care and $\mathrm{P}=0.02$ for skin test 


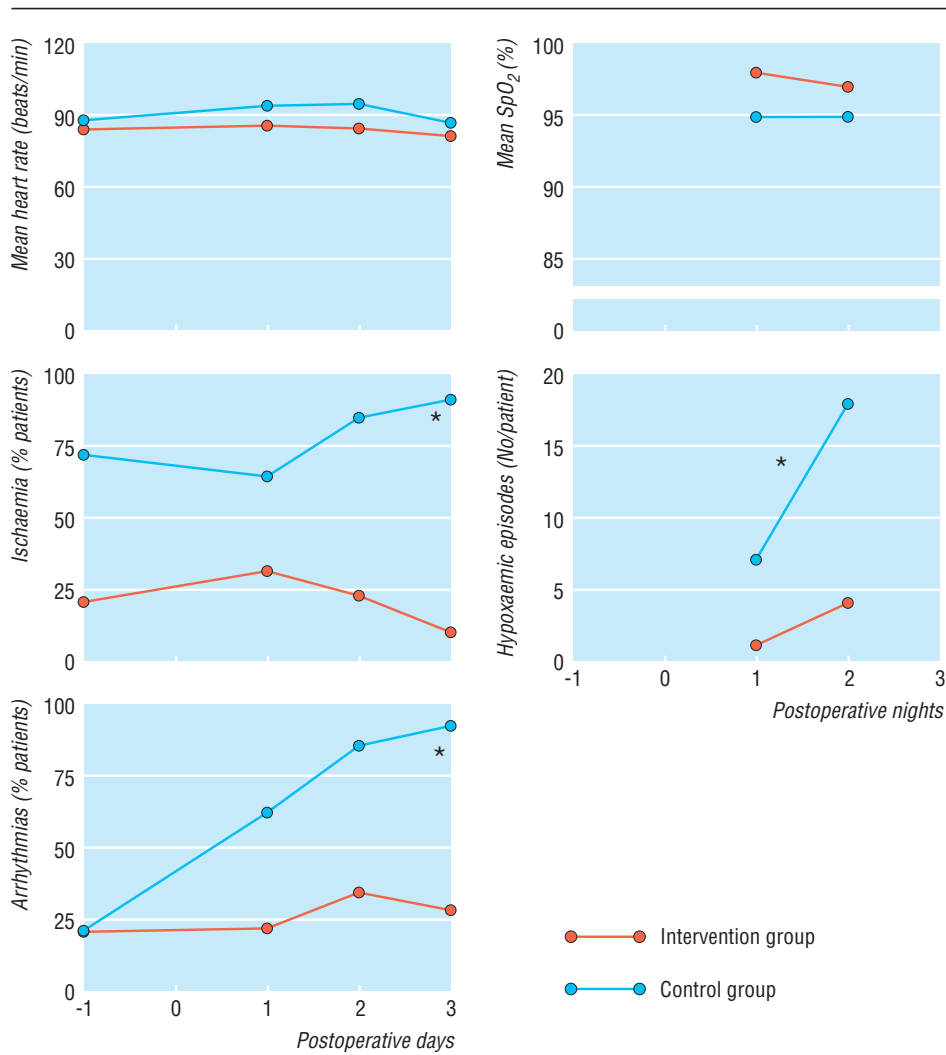

Fig 3 Median values on perioperative electrocardiography of all patients $(n=16+19)$ and postoperative pulse oximetry of patients from two centres $(n=14+12)$ undergoing colorectal surgery. ${ }^{*}$ Significance between groups (area under curve) $P \leqslant 0.05$
There was no significant difference in length of hospital stay: 8 days (3-41) versus 10 (4-46), respectively. Before the operation the delayed type hypersensitivity reactions were significantly larger in the abstinence group compared with the control group, while there was no difference postoperatively (fig 2). Myocardial ischaemia and arrhythmias occurred less often in the intervention group; there were also significantly fewer episodes of sudden hypoxaemia. All patients had a mean arterial oxygen saturation above $90 \%$ on all study nights (fig 3). The response surgical stress, as assessed by heart rate and plasma concentrations of catecholamines and interleukin 6, was significantly smaller in the intervention group, while mean arterial pressure, serum concentration of cortisol, and plasma concentration of glucose did not differ significantly between the groups (fig 4).

\section{Discussion}

Our results show that 1 month of preoperative abstinence in alcohol misusers reduces postoperative morbidity. Correspondingly, the need for nurse care was lowered. The high complication rate in the control patients, who continued to drink, is comparable with that seen in previous studies in alcohol misusers. ${ }^{1-4}$ Although reduced, the postoperative morbidity in the intervention group was still higher $(31 \%)$ than that seen in most studies in unselected colorectal patients, though a wide range has been reported. ${ }^{11} 12$ The mechanism of the improved outcome after intervention is probably reversibility of the ethanol induced organ dysfunction as a result of abstinence. ${ }^{5}$

\section{Specific complications}

Postoperative infections are related to preoperative immunosuppression. $^{13}$ The preoperative immune response in the intervention group improved significantly compared with the response in the control patients. There was no significant difference with regard to infectious outcome $(25 \%$ v $53 \% ; \mathrm{P}=0.17)$ between the groups. The postoperative immune response was low in both groups. The improved immunity after abstinence corresponds with our previous results in alcohol misusers who did not undergo surgery. ${ }^{14}$

Holter recording before surgery showed that in the group who did not abstain from alcohol misuse there were significantly more patients with myocardial ischaemia, which may explain the increased incidence of postoperative ischaemia seen in this group compared with the intervention group. These results may reflect alcohol induced cardiomyopathy, which improves after 1-3 months of sobriety. ${ }^{15}$ As postoperative myocardial ischaemia is related to serious cardiac complications,${ }^{17} 1$ month of abstinence may improve cardiac outcome in alcohol abusers.

Hypoxaemia after major surgery may contribute to cardiac and wound complications. ${ }^{18}$ The increased development of sudden episodic hypoxaemia in the patients who continued to drink may be due to the altered sleep physiology described in chronic alcohol abusers ${ }^{19}$ although a relation to the higher incidence of pulmonary complications in this group cannot be excluded. Sleep deterioration with high prevalence of apnoeic and hypopnoeic episodes may continue for 
3-6 weeks in detoxified misusers. ${ }^{19}{ }^{20}$ The incidence of postoperative episodic hypoxaemia in the intervention group is comparable with that seen in a group of unselected surgical patients. ${ }^{18}$

\section{Surgical stress response}

Response to surgical stress is mediated by cytokines and hormones, and excess stress is thought to be deleterious. Surgical trauma increases the activity of the hypothalamic-pituitary-adrenal axis and the sympathetic activity more in chronic misusers than in non-misusers. ${ }^{2}$ We found that the response to surgical stress was reduced in the group intervention, as measured by heart rate and catecholamine concentrations, while serum cortisol concentration was only insignificantly lower in the intervention group. These results are in accordance with those from studies in non-surgical patients, which reported normalised reaction of the central part of the hypothalamicpituitary-adrenal axis as well as normalised catecholamine response to (non-surgical) stress within 1 to 4 weeks after withdrawal. ${ }^{21}{ }^{22}$ The cortisol synthesis and metabolism, however, may still be disturbed after this period, ${ }^{21}$ which may explain the comparable high concentrations of serum cortisol in the groups.

The response to surgical stress includes production of interleukin 6, which besides immunological functions is the determinant stimulator of hepatocytes to produce acute phase proteins. Transient increased plasma concentrations of interleukin 6 after surgical intervention are associated with the injury severity and predict postoperative complications. ${ }^{23}$ In our study the interleukin 6 response was increased in both groups of patients compared with studies of unselected patients undergoing open colorectal resection. ${ }^{24}$ Similar to the enhanced hormonal response, the patients who continued to drink also showed significantly increased interleukin 6 concentrations compared with the abstinent group. High concentrations, above $5000 \mathrm{pg}$ / $\mathrm{ml}$, were found exclusively in patients who developed major complications. The clinical consequences of a smaller stress response in the intervention group may be a lower load on the already recovering target organs. Altogether, the smaller response may therefore contribute to the reduced postoperative morbidity.

\section{Bias}

The complete compliance with abstinence in the intervention group was probably because of the well known effect of brief intervention ${ }^{25}$ and the high level of motivation from the patients as well as information about the study. Though we have treated only the alcohol misuse, the intervention group may have changed other variables of lifestyle simultaneously. This was, however, not monitored. Other sources of bias include non-significant differences between the groups (table 1). Lower body mass index, fewer patients with hypertension, and less bleeding may contribute to the improved outcome in the intervention group, while a poorer prognostic index may act in the opposite direction.

The study population was identified by a specific interview concerning daily consumption, based on the memory of the patients. Underestimation is more pronounced with increasing drinking, ${ }^{26}$ and inclusion of non-misusers therefore seems improbable. In conclu-
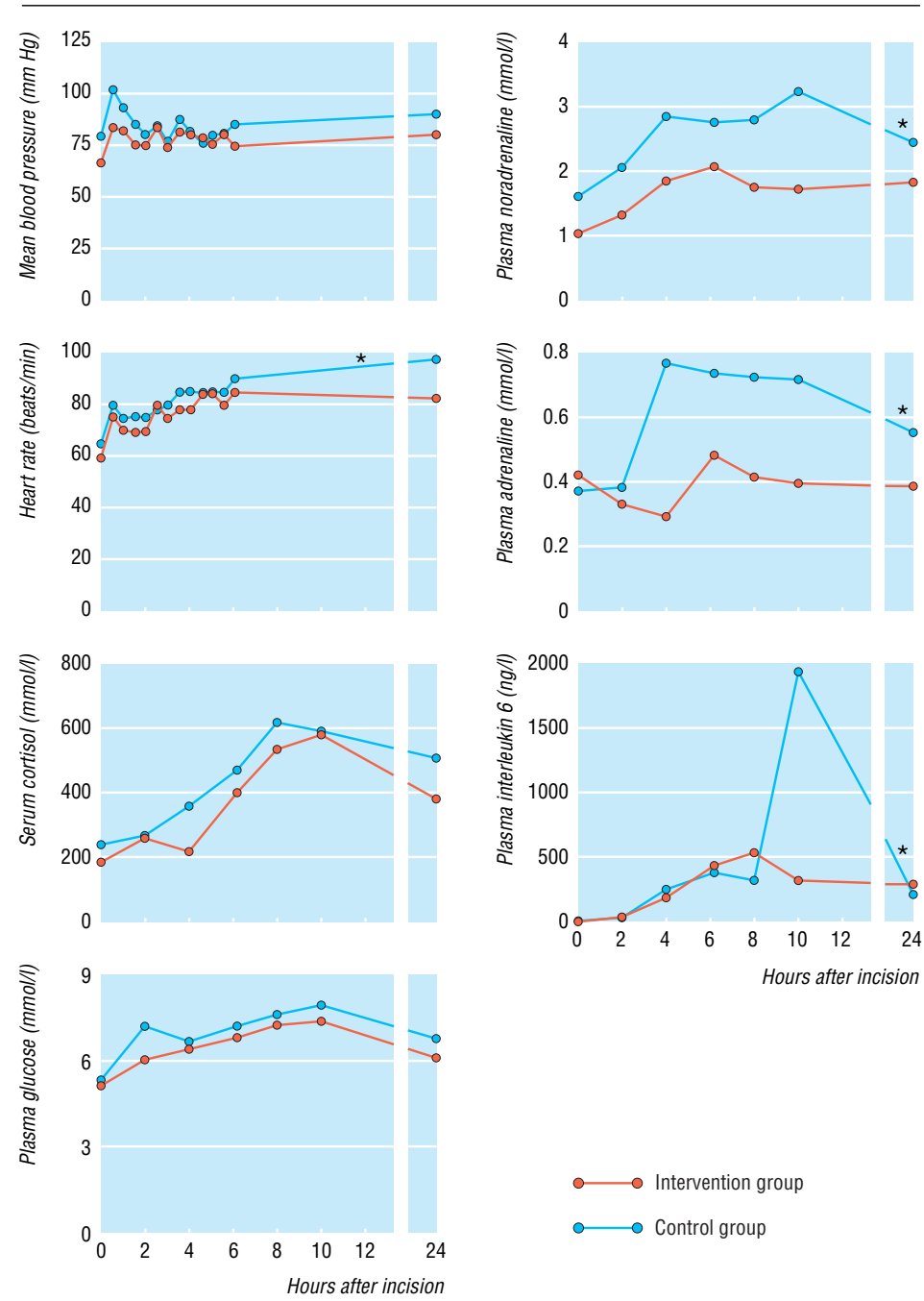

Fig 4 Median values for responses to surgical stress. * Significance between groups (area under curve) $P \leqslant 0.05$

sion, alcohol misuse should be included in the preoperative assessment of surgical risk and withdrawal recommended for at least 1 month before the operation whenever possible.

We thank Professor Per Christoffersen, department of pathology, Hvidovre Hospital, for histological examination of

\section{Key messages}

- Recent data have shown alcohol misusers to have a threefold increase in postoperative morbidity

- In misusers recovery from organ dysfunction induced by alcohol is seen after abstinence

- Abstinence from alcohol for 1 month before surgery reduces postoperative morbidity after colorectal surgery

- Mechanisms may involve reduced responses to surgical stress and improved cardiac and immune dysfunction

- Withdrawal from alcohol before an operation is recommended in alcohol abusers 
liver biopsies and Annie Høj and Karin Hoborg Juhl for laboratory assistance.

Funding: Danish Ministry of Health's fund for Alcohol Research provided grant for this work (No 1319-46-1995).

Contributors: HT initiated the research and coordinated the formulation of the primary study hypothesis, discussed core ideas, designed the protocol, collected and analysed the data, and wrote the paper. JR participated in the study design, analyses (pulse oximetry), interpretation of the data, and writing the paper. HJN participated in the study design, analyses (immune response), and interpretation of the data and edited the paper. VR participated in the data analyses (Holter tape recording) and edited the paper. $\mathrm{CH}$ and IKP participated in study design, data collection, and paper editing. HK discussed core ideas and participated in the protocol design, interpretation of the data, and writing the paper. HT, JR, and HK are guarantors of the paper.

1 Spies CD, Nordmann A, Brummer G, Marks C, Conrad C, Berger C, et al. Intensive care unit stay is prolonged in chronic alcoholic men following tumor resection of the upper digestive tract. Acta Anaesthesiol Scand 1996; $40: 649-56$

2 Tønnesen H, Petersen KR, Højgaard L, Stokholm KH, Nielsen, HJ, Knigge U, et al. Postoperative morbidity among symptom-free alcohol misusers. Lancet 1992;340:334-7.

3 Felding C, Jensen LM, Tønnesen H. Influence of alcohol intake on postoperative morbidity after hysterectomy. Am J Obstet Gynecol 1992;166:66770 .

4 Tønnesen H, Schütten BT, Jørgensen BB. Influence of alcohol on morbidity after colonic surgery. Dis Colon Rectum 1987;30:549-51.

5 Tønnesen H. The alcohol patient at surgery. Alcohol Alcohol (in press).

6 Simms JM, Smith JAR, Woods HF. A modified prognostic index based upon nutritional measurements. Clin Nutr 1982;1:71-9.

7 Goldman L, Caldara DL, Nussbaum SR, Southwick FS, Krogstad D, Murray $\mathrm{B}$, et al. Multifactorial index of cardiac risk in non-cardiac surgical procedures. N Engl J Med 1977;297:845-50.

8 American Society of Anesthesiologists. New classification of physical status. Anesthesiology 1965;24:111.

9 Rosenberg J, Rasmussen V, von Jessen F, Ullstad T, Kehlet H. Late postoperative episodic and constant hypoxaemia and associated ECG abnormalities. Br J Anaesth 1990;65:684-91.

10 Appel E, Bayer P, Hajdu P, Palm D, Shofer J, Uihlein M. Determination of plasma catecholamines by means of radioenzymatic labelling and high pressure liquid chromatographic separation. Naunyn Schmiedebergs Arch Pharmacol 1981;315:233-9.
11 Vignali A, Fazio VW, Lavery IC, Milsom JW, Church JM, Hull TL, et al. Factors associated with the occurrence of leaks in stapled recta anastomoses: a review of 1,014 patients. J Am Coll Surg 1997;185:105-13.

12 Bokey EL, Chapuis PH, Fung C, Hughes WJ, Koorey SG, Brewer D, et al. Postoperative morbidity and mortality following resection of the colon and rectum for cancer. Dis Colon Rectum 1995.38:480-7.

13 Christou NV. Host-defence mechanisms in surgical patients: a correlative study of the delayed hypersensitivity skin-test response, granulocyte function and sepsis. Can J Surg 1985;28:39-49.

14 Tønnesen H, Kaiser AH, Nielsen BB, Pedersen AE. Reversibility of alcohol-induced immune depression. Br J Addict 1992;87:1025-8.

15 Kelbæk H, Nielsen BM, Eriksen J, Rabol A, Christensen NJ, Lund JO, et al Left ventricular performance in alcoholic patients without chronic liver disease. Br Heart J 1987;58:352-7.

16 La Vecchia L, Bedogni F, Loredana B, Bevilacqua P, Ometto R, Vincenzi M. Prediction of recovery after abstinence in alcoholic cardiomyopathy: role of hemodynamic and morphometric parameters. Clin Cardiol 1996;19:45-50.

17 Mangano DT, Goldman L. Preoperative assessment of patients with known or suspected coronary disease. N Engl J Med 1995;333:1750-6.

18 Rosenberg J, Kehlet H. Late postoperative hypoxemia. In: Kinney JM, Tucker HN, eds. Physiology, stress and malnutrition: functional correlates, nutritional intervention. New York: Lippincott-Raven Publishers, 1997.

19 Williams HL, Rundell OH Jr. Altered sleep physiology in chronic alcoholics: reversal with abstinence. Alcohol Clin Exp Res 1981;5:318-25.

20 Le Bon O, Verbanck P, Hoffmann G, Murphy JR, Staner L, De Groote D, et al. Sleep in detoxified alcoholics: impairment of most standard sleep parameters and increased risk for sleep apnea, but not for myoclonias - a controlled study. J Stud Alcohol 1997;58:30-6.

21 Marchesi C, Chiodera P, Ampollini P, Volpi R, Coiro V. Beta-endorphin, adrenocorticotropic hormone and cortisol secretion in abstinent alcoholics. Psychiatr Res 1997;72:187-94.

22 Martin PR, Gibbs SJ, Nimmerricher AA, Riddle WR, Welch LW, Willcott MR. Brain proton magnetic resonance spectroscopy studies in recently abstinent alcoholics. Alcohol Clin Exp Res 1995;19:1078-82.

23 Damas P, Ledoux D, Nys M, Vrindts Y, De Groote D, Franchimont P, et al. Cytokine serum level during severe sepsis in human IL-6 as a marker of severity. Ann Surg 1992;215:356-62.

24 Stage JG, Schulze S, Møller P, Overgaard H, Andersen M, RebsdorfPedersen VB, et al. Prospective randomized study of laparoscopic versus open colonic resection for adenocarcinoma. BrJ Surg 1997;84:391-6.

25 World Health Organisation. A cross-national trial of brief intervention with heavy drinkers. Am J Public Health 1996;86:948-55.

26 Popham RE, Schmidt W. Words and deeds: the validity of self report data on alcohol consumption. J Stud Alcohol 1981;42:355-8.

(Accepted 18 February 1999)

\section{Editorial by Latham \\ Departamento \\ Materno Infantil, \\ Fundação \\ Universidade do \\ Rio Grande, Rio \\ Grande do Sol, \\ Brazil Juraci A \\ César, \\ assistant professor \\ Departamento de Medicina Social, \\ Universidade \\ Federal de Pelotas, \\ Rio Grande do Sol \\ Cesar G Victora, \\ professor \\ Fernando C Barros, \\ professor \\ Iná S Santos, \\ associate professor \\ continued over}

BMJ 1999;318:1316-20

\section{Abstract}

Objective To determine whether breast feeding protects infants against pneumonia and whether the protection varies with age.

Design Nested case-control study.

Setting Pelotas, southern Brazil.

Subjects Cases were 152 infants aged 28-364 days who had been admitted to hospital for pneumonia. Controls were 2391 cases in a population based case-control study.

Main outcome measure Odds ratio of admission for pneumonia according to type of milk consumed (breast milk alone, breast and formula milk, or formula milk and other fluids only), use of fluid supplements apart from formula milk, and use of solid supplements.

Results Infants who were not being breast fed were 17 times more likely than those being breast fed without formula milk to be admitted to hospital for pneumonia (95\% confidence interval 7.7 to 36.0$)$. This relative risk was 61 (19.0 to 195.5) for children under 3 months old, decreasing to 10 (2.8 to 36.2) thereafter. Supplementation with solids was associated with a relative risk of 13.4 (7.6 to 23.5) for all infants and 175 (21.8 to 1405.1) for those under 3 months old. Conclusion Breast feeding protects young children against pneumonia, especially in the first months of life. These results may be used for targeting intervention campaigns at the most vulnerable age groups.

\section{Introduction}

Pneumonia is the leading cause of death in children under 5 years old worldwide, ${ }^{12}$ and breast milk is the most important food in the first year of life.

Several studies in less developed countries have assessed the effect of breast feeding on the risk of developing acute lower respiratory infections, particu- 